\title{
Diversity and complexity in the acoustic behaviour of Dacyllus flavicaudus (Pomacentridae)
}

\author{
Eric Parmentier · Loïc Kéver · Margarida Casadevall • \\ David Lecchini
}

Received: 14 March 2010/Accepted: 17 June 2010/Published online: 3 July 2010

(C) Springer-Verlag 2010

\begin{abstract}
Synchronous underwater audio-video recordings and a passive acoustic detector were used to study the behaviour of Dascyllus flavicaudus. These damselfish produced sounds during six different behaviours and showed three different colour patterns while doing so. These sounds can be grouped into three classes: sounds associated with (1) fighting; (2) mating/visiting and (3) chasing and signal jumps. Moreover, the evolution of the different kinds of sound is discussed: the first calls could be a single pulse originating in teeth snapping. Modifications in the rhythm and number of pulses allowed the fish to build new messages. Daily recordings showed that sound production rates were higher at sunrise and sunset than during the day and that no sound was produced during the night. However, the kinds of call were different: sunrise sounds seemed mainly associated with mating/visiting, whereas the sounds associated with chasing and to signal jumps were mainly found at sunset.
\end{abstract}

Communicated by D. Goulet.

E. Parmentier $(\square) \cdot$ L. Kéver

Laboratoire de Morphologie Fonctionnelle et Evolutive, Institut de chimie, Bât. B6c, Université de Liège, 4000 Liège, Belgium

e-mail: E.Parmentier@ulg.ac.be

M. Casadevall

Unitat de Biologia Animal, Facultat de Ciències, Universitat de Girona, Campus de Montilivi s/n, 17071 Girona, Spain

D. Lecchini

Institut de Recherche pour le Développement (IRD), UR 128 (CoRéUs), 101 Promenade Roger Laroque, BP A5, Noumea 98848, New Caledonia

\section{Introduction}

Damselfishes (Pomacentridae) are well-known vocal species from the coral reefs and at least eight (Abudebduf, Amphiprion, Chromis, Dascyllus, Hemichromis, Pomacentrus, Premnas, Stegastes) of the $\sim 29$ genera have been reported to produce sounds in numerous acoustic studies (Amorim 2006; Maruska et al. 2007). Sound production in a species from the basal clade (Plectroglyphidodon lacrymatus) suggests that pomacentrids are derived from an ancestral taxon capable of sound production (Parmentier et al. 2006). The mechanism of sound production could be a synapomorphy for the family (Parmentier et al. 2007). Most of these sounds consist of trains of pulses. The number of pulses in a call and their temporal properties (pulse length, pulse interval) appear to be the most important factors in species recognition (Myrberg and Spires 1972; Ha 1973; Myrberg et al. 1978; Spanier 1979). Species also present a huge overlap, and the individual would need to sample more than one sound and potentially use other cues to discriminate between species (Parmentier et al. 2009). Furthermore, Mann and Lobel (1995) reported that the damselfish Dascyllus albisella repeats sounds hundreds of times a day.

Interspecific comparison is also difficult because sound production is used in a variety of behaviours. Several studies have reported the ability of species belonging to different genera to produce different kinds of sounds in different contexts such as courtship, aggression towards heterospecifics and conspecifics, nest visiting or nest cleaning (Myrberg 1972; Mann and Lobel 1998; Maruska et al. 2007). Furthermore, it seems that these fish also present activity peaks. Dascyllus albisella usually produce more sounds at sunset, but they begin to call around midnight on spawning days (Mann and Lobel 1995). 
Pomacentrus partitus present two peaks, one at sunset and the second at sunrise (Myrberg 1972; Steinberg et al. 1965).

In the Dascyllus species, courting males prepare the nest by cleaning pieces of coral and chasing other fishes away from the site. Males then perform courtship displays or signal jumps to attract females. The courtship dip consists of a male rising in the water column and then rapidly swimming downwards while making a pulsed sound (Lobel and Mann 1995). Females spawn adhesive eggs in nests in male territories and the eggs are tended by males until hatching (Thresher 1984). After 2-3 days, hatched larvae drift into the open sea where they grow for a period of 22-24 days (Brothers et al. 1983; Wellington and Victor 1989). As with most of the coral reef fishes, the settlement fluctuates considerably across a variety of time scales: daily, lunar phase, monthly or longer (Doherty and Williams 1988; Booth 1991). In Moorea (French Polynesia), Dascyllus flavicaudus colonizes the reef throughout the year, but the settlement rate seems to be higher during nights of the austral winter (Dufour and Galzin 1993; Schmitt and Holbrook 1999). This species lives in colonies of 3-10 individuals and is usually associated with Pocillopora, Acropora, Montipora and Porites (Schmitt and Holbrook 1999; Asoh 2004).

The aim of this study was twofold. The first approach used video-sound recordings to describe as well as possible the sounds produced during different behaviours in the damselfish Dascyllus flavicaudus. Passive acoustics is becoming a tool for studying the spatial and temporal nature of many aspects of fish biology (e.g. location and timing of spawning) for fishes that actively produce advertisement calls (Fine and Thorson 2008; Gannon 2008). The second approach consisted of recording the sounds in different Dascyllus flavicaudus groups in order to discover whether there were some temporal cycles of sound production in this species.

\section{Materials and methods}

Sound recordings

Field recordings of sound production by $D$. flavicaudus were made at Opunohu Bay, Moorea lagoon $\left(17^{\circ} 29^{\prime} \mathrm{S}\right.$, $149^{\circ} 52^{\prime} \mathrm{W}$, French Polynesia). Recording sessions, each lasting from 1 to $4 \mathrm{~h}$, were made from January to March 2009 at a depth of between 1 and $5 \mathrm{~m}$. Sea water in the lagoon was on average $29^{\circ} \mathrm{C}$.

Recordings of sound production by Dascyllus flavicau$d u s$ were made using a SONY HDD video camera placed in a housing (HC3 series, Ocean Images, Cape Coral, Fl) and coupled with an external hydrophone (High Tech. Inc.) with a flat response of $20 \mathrm{~Hz}$ to $20 \mathrm{kHz}$ and a nominal calibration of $-164 \mathrm{dBV} \mu \mathrm{Pa}^{-1}$ (Loggerhead Instruments Inc., Sarasota, Fl). Recordings were made while diving or by placing the housing in front of the coral patch.

Sounds and their associated behaviours were analysed on the basis of the videos and field observations. When associated with sounds, behaviours were described and sounds were extracted in .wav files using the AoA audio extractor setup freeware (version 1.2.5). Sounds were digitized at $44.1 \mathrm{kHz}$ (16-bit resolution), low-pass filtered at $1 \mathrm{kHz}$ and analysed using AvisSoft-SAS Lab Pro 4.33 software. Only the sounds with a good signal to noise ratio were used in the analysis. Temporal features were measured from oscillograms, and frequency parameters were obtained from power spectra. The following sound parameters were measured: sound duration; number of pulses in a sound; pulse period (measured as the average peak-to-peak interval between consecutive pulses in the entire sound; inter-pulse interval or IPI (measured as the time from the end of one pulse to the beginning of the next); pulse length (measured as the time from the beginning of one pulse and its end); dominant frequency and relative intensity $(\mathrm{dB})$.

Recording of daily cycles was made with a Digital Spectrogram Recorder (DSG, Loggerhead Instruments Inc, Sarasota, FL). The DSG recorder is a long-term, low-power recorder of acoustic signals. The master sample rate was $40 \mathrm{kHz}$, and the hydrophone sensitivity was $-186 \mathrm{dBV} \mu \mathrm{Pa}^{-1}$. The system was scheduled to record for $15 \mathrm{~min}$ every $60 \mathrm{~min}$. The DSG was first placed for a complete lunar month next to a colony with approximately eight D. flavicaudus. After that, the DSG was placed next to 14 different colonies in the lagoon for a period of $24 \mathrm{~h}$ in each case. Sounds were digitized at $22 \mathrm{kHz}$ (16-bit resolution), low-pass filtered at $2 \mathrm{kHz}$ and analysed using AvisSoft-SAS Lab Pro 4.33 software. Manual analysis consisted of identifying the D. flavicaudus sounds. These sounds were counted, and the number of pulses/sound was noted.

\section{Sex determination}

Dascyllus flavicaudus were collected by scuba diving in the Moorea Lagoon. At the time of collection, the behaviour of each fish and its colour pattern were noted. All these fish were immediately euthanized in MS-222, measured to the nearest $\mathrm{mm}$ and placed in 5\% formaldehyde fixative solution for future use as histological sections. The fish were then dissected, and the gonads were removed and embedded in 2-hydroxyethyl methacrylate (GMA). Serial crosssections (6-8 $\mu \mathrm{m}$ thick) of the gonads were stained with toluidine blue ( $\mathrm{pH} 4.4)$ and with basic fuchsin-methylene blue. 
Data analysis

The analysis assumed that the pulses were independent. For analysis of acoustic data, each sonic variable (pulse length, pulse number, inter-pulse interval, main frequency, pulse period, relative amplitude) was first correlated against the other. This showed that the pulse period was highly correlated with the IPI $(r=0.82, P<0.01)$ and that the number of pulses was highly correlated with sound duration $(r=0.93, P<0.01)$. Consequently, pulse period and sound duration were removed from statistical analysis involving principal component analysis (PCA). This test was used to identify the variables explaining the highest level of variance among all the recorded behaviours.

Statistical analyses were carried out with Statistica 8.0. The Shapiro-Wilk $W$ test was used to test the normality of the data. The non-parametric Kruskal-Wallis test was then used to compare the characteristics of the different behaviours and post hoc paired comparisons.

\section{Results}

\section{Behaviour/sounds}

Sounds were produced by males during six different kinds of behaviour (Figs. 1, 2). The main characteristics of their associated sounds are shown in Table 1.

(1) The sound associated with the signal jump (SJ) consisted of a male rising in the water column and then rapidly swimming down (Fig. 1) while making a pulsed sound. This behaviour was initiated when female(s) entered the male territory or in response to signal jumps made by other males. The male territory spread from $50 \mathrm{~cm}$ to about $1 \mathrm{~m}$ around nests usually situated at the base of a coral colony.

(2) The visiting sound is produced by males when females visit the nests. In this case, males and females perform a pseudo-spawning behaviour during visiting, with both passing over the nesting surface. In Dascyllus albisella, this behaviour is the same as that performed during actual spawning when the mating sound is produced (Mann and Lobel 1998). We were not able to differentiate the two kinds of behaviour, and they were therefore grouped in a single group: the mating/visiting (MV) group.

(3) The conspecific chase (CC) consisted of a simple pursuit and was made when males chased other D. flavicaudus away from their territory area.

(4) The heterospecific chase (HC) corresponded to the pursuit of fishes of another species. This was performed by territorial males.
(5) During conspecific fighting (CF), fish were face-toface and made coming and going movements. Simultaneously, both fish rotated around a common axis. During this rotation, fish always tried to keep their head facing their adversary. During these fights, submission postures were sometimes observed: the fish stopped swimming and showed its flank. It was not easy to determine which of the fish produced sounds because both specimens showed an identical behaviour when fighting.

(6) The behaviour of heterospecific fighting (HF) was comparable to that displayed during conspecific fighting. It was observed only in some Acanthuridae eating algae on the coral colonies next to the nests. No submission behaviour was observed, and no sound was detected in the Acanthuridae.

Signal jump (SJ), MV and CC were associated with long sounds, with an average duration between 160 and $240 \mathrm{~ms}$ (Table 1). The longer duration of these three sounds was due to their number of pulses (Fig. 3), which was on average 6.7, 4 and 5 for SJ, MV and CC, respectively. Inside this group, MV clearly presented a longer inter-pulse period $(35 \pm 7 \mathrm{~ms})$ than $\mathrm{SJ}(22 \pm 6 \mathrm{~ms})$ and $\mathrm{CC}$ (21 $\pm 5 \mathrm{~ms}$ ). MV also produced the quietest call (Table 1). The mean number of pulses was $<2$ for both fighting calls and for the heterospecific chases. Moreover, more than $50 \%$ of sounds had only one pulse in $\mathrm{HC}, \mathrm{CF}$ and $\mathrm{HF}$ (Fig. 3). Fish performing HC were able to produce sounds with 8 pulses, although there were no more than four pulses during both kinds of fighting behaviour.

In order to compare the different kinds of sound, principal component analysis (PCA) was carried out on acoustic properties, highlighting the different behaviours associated with the sounds (Fig. 4). According to the biplot, the first axis (PC1) was principally loaded by variables describing the IPI and the sound amplitude and the second axis (PC2) by the number of pulses and the pulse duration. The plot of the behaviours along the first two principal components (PC1, 56.77\% and $\mathrm{PC} 2,22.5 \%$ ) highlighted two clusters with a small overlap (Fig. 4). The first cluster involved signal jumps and conspecific chases. The second cluster included all other calls (MV, HC, CF, HF) but appeared less homogenous. Typically, the first cluster possessed a shorter IPI, but a higher level of pulses and a louder call than the sounds of the second cluster.

None of the variables possessed a normal distribution in the six behaviours. A non-parametric Kruskal-Wallis test was therefore used to compare the characteristics of the different behaviours and a post hoc test to compare pairs of groups. This showed that the variables (number of pulses, IPI, sound amplitude, pulse duration) were not necessarily useful for identifying a given sound and that they could be 
Fig. 1 Behaviours associated with sound production in the damselfish Dascyllus

flavicaudus. In each case, the sound production is attributed to the damselfish with a white head and black body. The numbers refer to the chronology of the behaviour. The three small curves in front of the head of the caller represent the time of the behaviour at which there is sound production
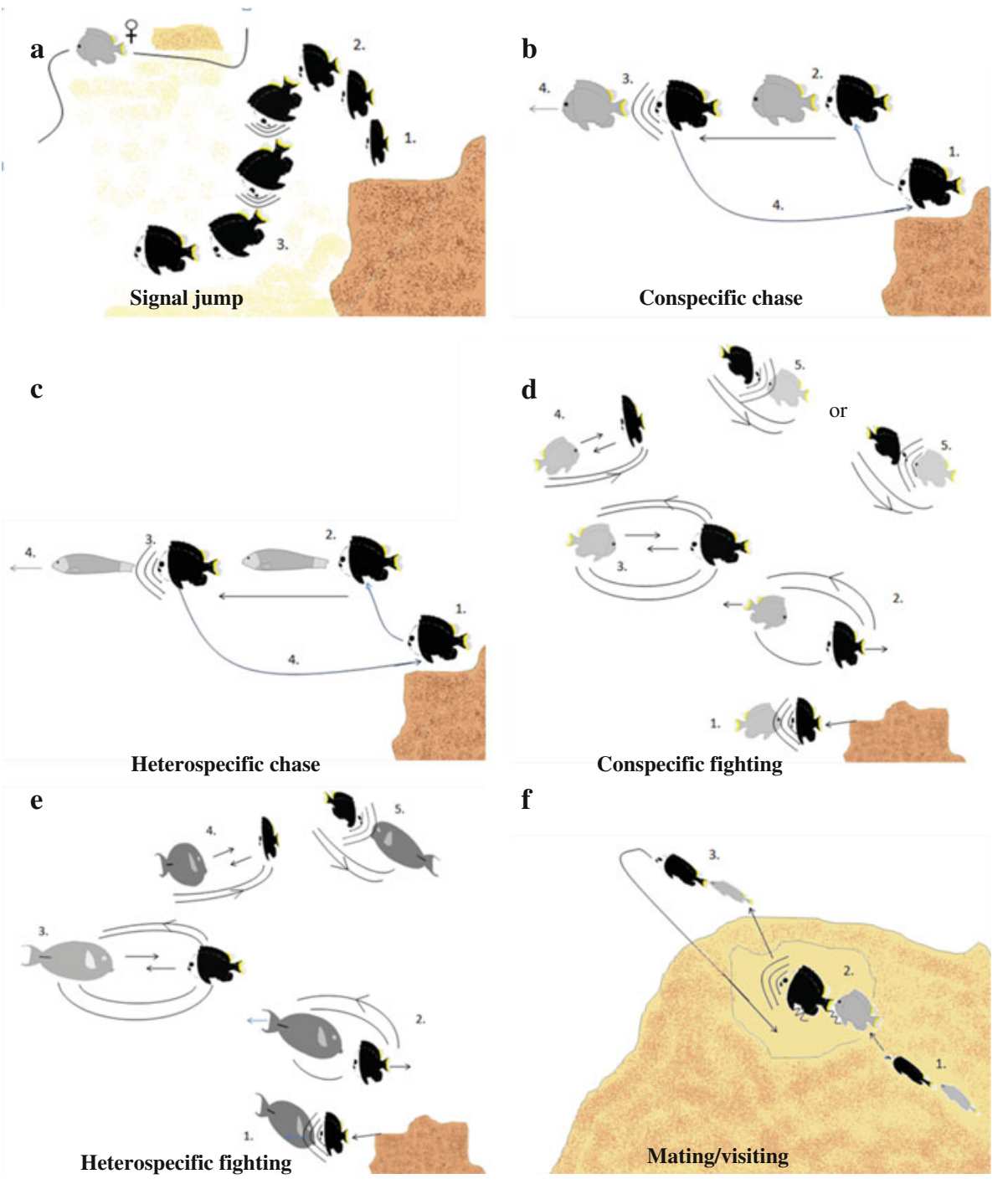

f
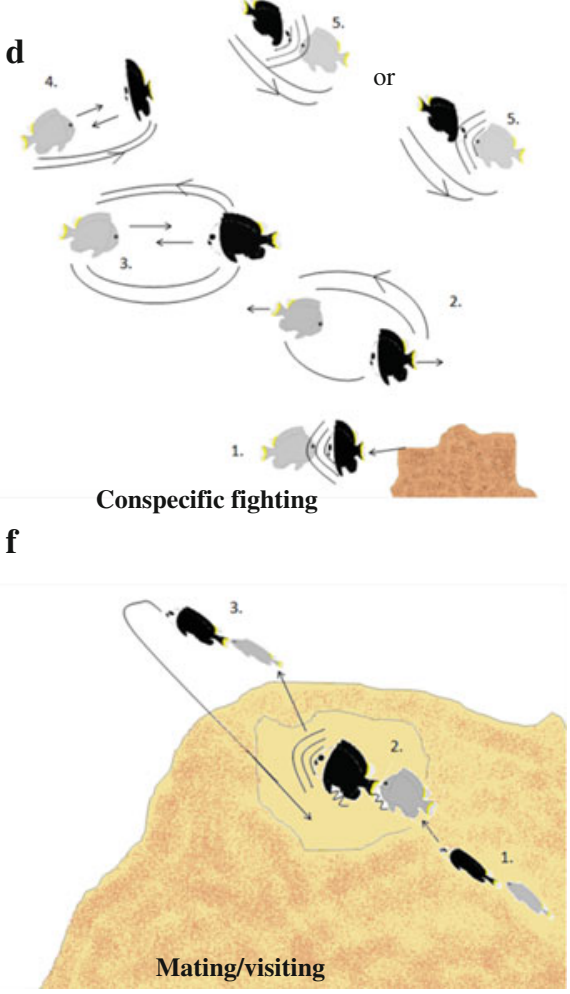

used in certain cases only. The number of pulses and the pulse duration variables were interesting because they allowed the discrimination of SJ and CC, which were found in the first cluster of the PCA analysis. Pulse duration was the least useful variable for distinguishing the different sounds. This variable could only distinguish SJ from MV and SJ from CC. The pairwise comparison also highlighted that sounds related to conspecific and heterospecific fighting were dissociated only on the basis of the sound amplitude.

Means for the frequencies of the six behaviours were between 490 and $618 \mathrm{~Hz}$ and present large overlaps (Table 1). These results are not really informative in distinguishing the different sounds. Usually, the frequency associated with the most energy is used to describe the sound. In D. flavicaudus, the sonic signature presents three mains peaks of frequency, but the most intense frequency is not systematically related to the same peak (Fig. 5).
It was observed many times during this study that D. flavicaudus are able to change their general appearance very rapidly $(<5 \mathrm{~s})$. We therefore investigated whether a given appearance was linked to a particular behaviour. Different sounds were produced while the fish displayed different colour patterns (Fig. 6): (1) black body and black head, (2) black body and white head and (3) white body and white head. The dominant colour pattern in D. flavicaudus is black body and head in both males and females. Fish displaying the signal jump behaviour never showed this colour pattern during our recordings. The black body with white head is the main pattern associated with sound production. Males and females can display this pattern (Table 2). We observed that calls were rarely produced when fish had a white body and white head. Among the six specimens with a white head and body at the time of capture, five were identified as female and one as male (Table 2). Fish can also change their colour pattern without making sounds. 
Fig. 2 Oscillograms of the different kinds of call produced by the damselfish Dascyllus flavicaudus
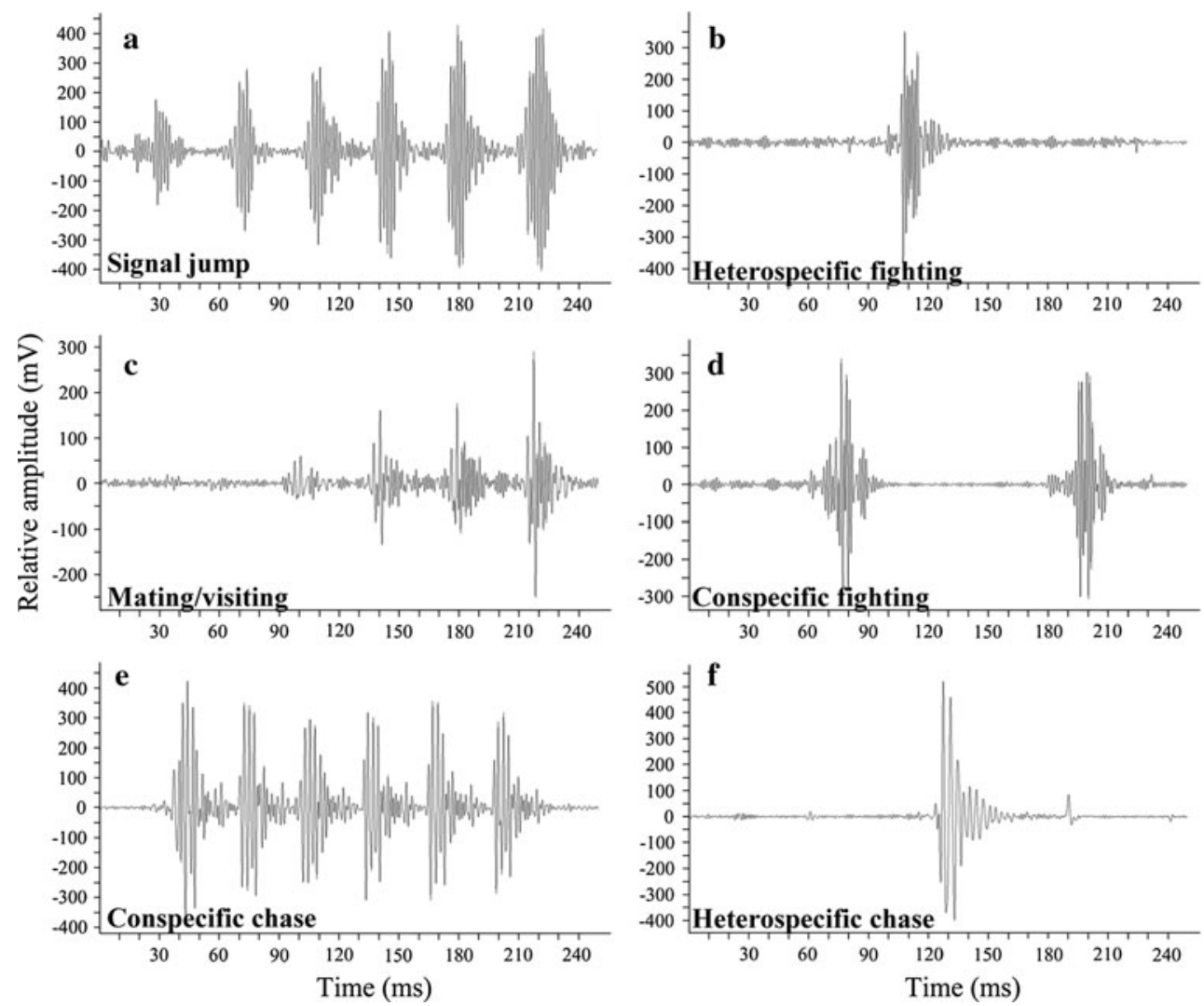

Table 1 Comparison of the different call characters in Dascyllus flavicaudus

\begin{tabular}{lcccccc}
\hline & Signal jump & Mating/visiting & $\begin{array}{l}\text { Conspecific } \\
\text { chases }\end{array}$ & $\begin{array}{l}\text { Heterospecific } \\
\text { chases }\end{array}$ & $\begin{array}{l}\text { Conspecific } \\
\text { fighting }\end{array}$ & $\begin{array}{l}\text { Heterospecific } \\
\text { fighting }\end{array}$ \\
\hline Sound duration & $241 \pm 58(118)$ & $163 \pm 74(49)$ & $160 \pm 65(102)$ & $43 \pm 53(54)$ & $42 \pm 34(54)$ & $50 \pm 62(16)$ \\
$\#$ pulsations/sound & $6.7 \pm 1.6(118)$ & $4.0 \pm 1.4(49)$ & $5.0 \pm 1.8(102)$ & $1.7 \pm 1.5(54)$ & $1.5 \pm 0.6(54)$ & $1.6 \pm 1.0(16)$ \\
Period (ms) & $38 \pm 6(673)$ & $49 \pm 8(145)$ & $36 \pm 5(439)$ & $38 \pm 8(37)$ & $46 \pm 19(34)$ & $55 \pm 12(9)$ \\
Pulse duration (ms) & $16 \pm 4(789)$ & $13 \pm 3(194)$ & $14 \pm 4(548)$ & $15 \pm 5(91)$ & $16 \pm 7(93)$ & $15 \pm 2(25)$ \\
Inter-pulse (ms) & $22 \pm 6(671)$ & $35 \pm 7(145)$ & $21 \pm 5(439)$ & $23 \pm 7(37)$ & $34 \pm 15(32)$ & $40 \pm 13(9)$ \\
Relative intensity (dB) & $-32.6 \pm 10.2(790)$ & $-45.2 \pm 5.1(194)$ & $-31.9 \pm 8.9(548)$ & $-38.4 \pm 9.5(91)$ & $-35.2 \pm 10.7(93)$ & $-43.2 \pm 6.0(25)$ \\
Frequency (Hz) & $500 \pm 133(787)$ & $490 \pm 125(192)$ & $591 \pm 104(543)$ & $539 \pm 167(90)$ & $618 \pm 118(93)$ & $509 \pm 197(25)$ \\
\hline
\end{tabular}

Mean $\pm \operatorname{SD}(N)$

\section{Call cycles}

Daily cycles were carried out on the basis of 40 days of recording and the use of 14 colonies. During the night, sound production was found to be low or absent (Fig. 7). During the day, D. flavicaudus was found to be a prolific caller. Some days, there were up to 3,600 calls (for a colony of eight fish). Although the variability in the call frequency can be great, it was possible to determine a temporal schema within a day. Two different peaks of sonic activity were significantly higher (post hoc test, $P<0.05$ ) than all the others. The first peak of sonic activity occurred at sunrise (between 0530 and 0600 hours in this study) with a mean call rate of $X \pm \mathrm{SD}=37 \pm 39$ sounds $15 \mathrm{~min}^{-1}$. The second peak of activity was the highest and occurred before sunset (between 1820 and 1840 hours in this study) with a mean call rate of $X \pm \mathrm{SD}=66 \pm 52$ sounds $15 \mathrm{~min}^{-1}$. The lowest call rate occurred in the afternoon (around 1500 hours) during which fish produced $X \pm \mathrm{SD}=17 \pm 28$ sounds $15 \mathrm{~min}^{-1}$.

Call duration showed variations during the day, as did the number of pulses. Consequently, these data suggested that different kinds of behaviour took place specifically at different periods of the day. At sunrise, the calls mainly consisted of 3 and 4 pulses. The dominant number of calls was 5 and 6 for the other periods. It is important to note here that sounds with 1 and 2 pulses were not counted. The establishment of the kind of behaviour concerns only the signal jump, mating/visiting and conspecific chasing, 
Fig. 3 Frequency distribution of pulse numbers in different kinds of call in Dascyllus flavicaudus
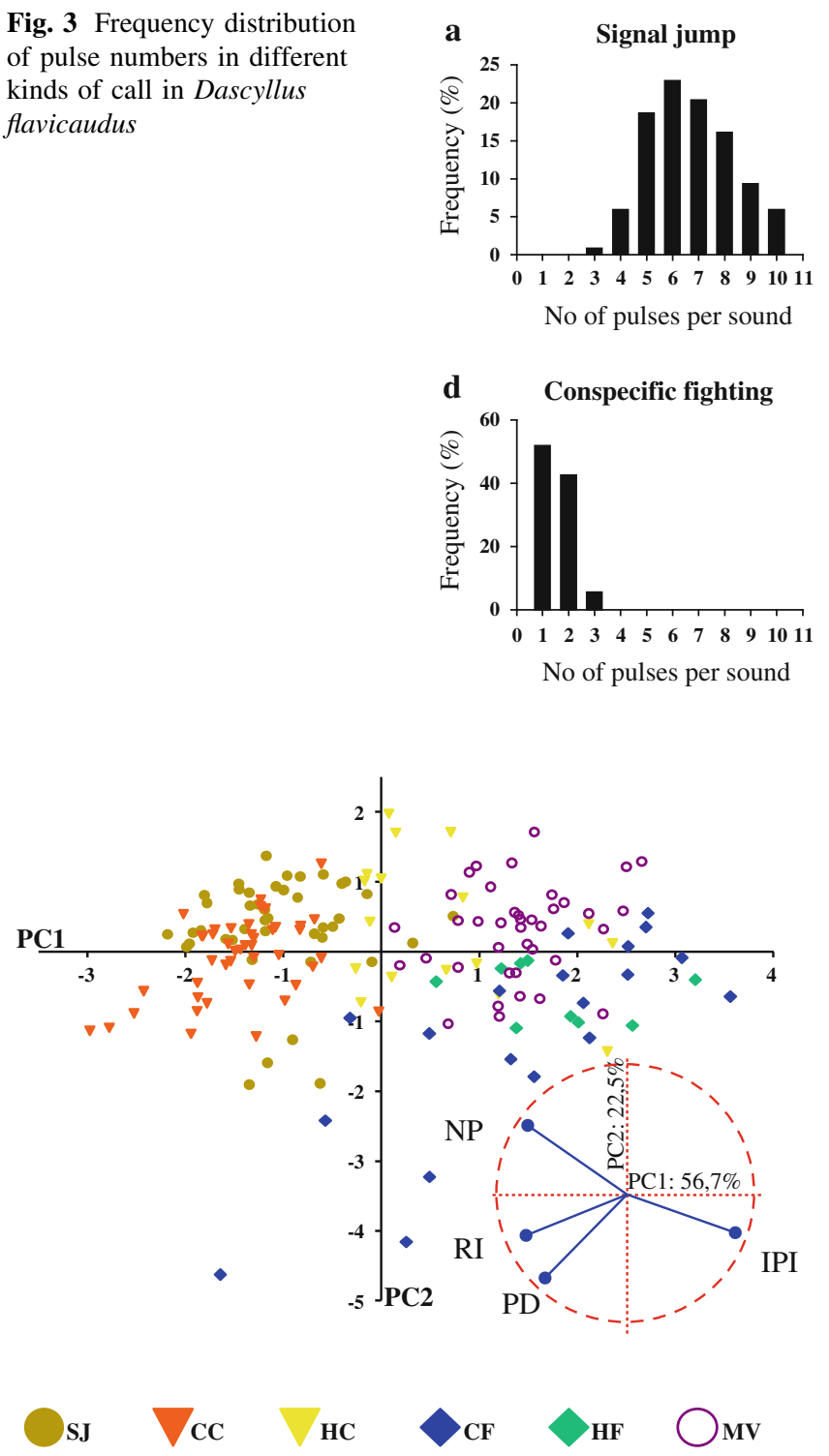

Fig. 4 Scatterplot from principal component analysis of the four acoustic parameters, whose loadings are shown in the projection of the variables on the factorial plan (dotted circle). Abbreviations of acoustic characteristics: IPI inter-pulse interval, $N P$ number of pulses, $P D$ pulse duration, $R I$ relative intensity. Abbreviations of behaviours: $C C$ conspecific chase, $C F$ conspecific fighting, $H C$ heterospecific chase, $H F$ heterospecific fighting, $M V$ mating/visiting, $S J$ signal jump

which have a mode of s, 3 and 5 pulses, respectively. At sunrise, the calls corresponded mainly to the mating/visiting behaviour. No videos were made at this time and it is still possible these calls correspond to a behaviour that was not observed in this study. The other periods of the day had a mode of 6 , corresponding mainly to the signal jump and the conspecific chase.

The continuous recording of a given colony of eight fish during a lunar month did not provide a particular pattern in call production (Fig. 8). As a minimum, this shows that in
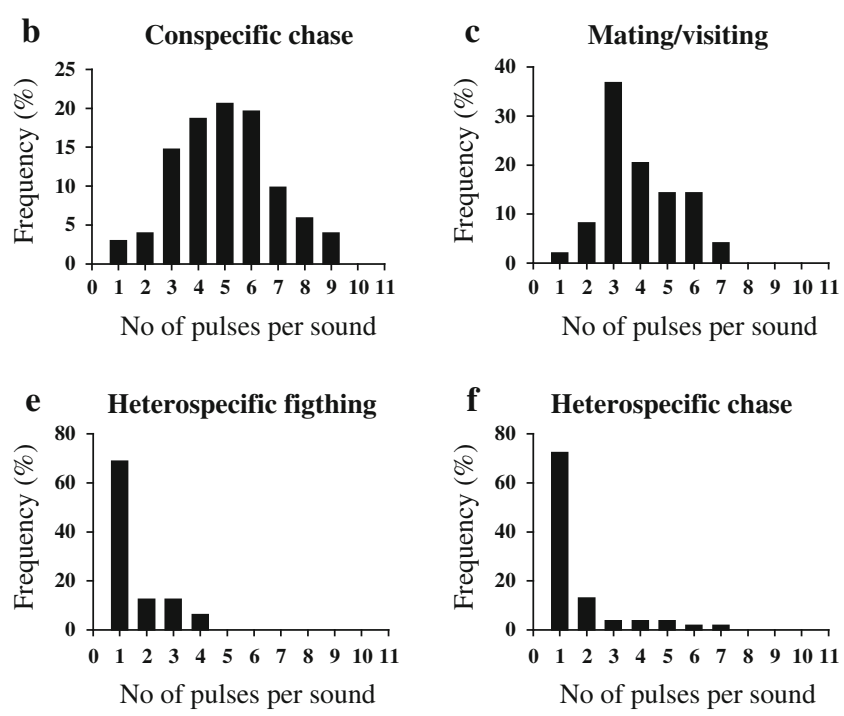

the same colony, the sonic activity at a given period of the day does not particularly reflect the activity of the whole day and that there is an important variability from day to day.

\section{Discussion}

Dascyllus flavicaudus males were shown to produce pulsed sounds during different behaviours. All these sounds were emitted at the same interval of frequency and had the same kind of sound spectrum, showing they were constructed on the basis of the same mechanism. Differences in the main frequency and in the duration of the pulses are related to fish size in Pomacentridae (Myrberg et al. 1993; Lobel and Mann 1995; Mann and Lobel 1997, Maruska et al. 2007; Colleye et al. 2009; Parmentier et al. 2009). Consequently, the differences between the calls, namely the number of pulses, the pulse period and the loudness are due to the fish physiology reflecting the behaviour and its motivational state. In this case, the different kinds of sounds could be derived from an ancestor call. The parsimony principle implies that this ancestral call is single. According to Parmentier et al. (2007), the sounds in clownfish are initiated by teeth collisions caused by rapid jaw closure attributed to a ligament between the hyoid bar and internal mandible. This ligament is homologous to the Pomacentridae and is likely to be involved in sound production throughout this large family (Parmentier et al. 2007). This functional movement seems to be an exaptation of the feeding mechanism, the ligament allowing mouth closure without the help of the adductor mandibulae muscles. The origin of the sound could be found in biting. Conspecific and heterospecific fighting sounds that occur before a display of aggressive behaviour with biting fit very well with 
Fig. 5 Power spectra of a pulse within the different calls of the damselfish Dascyllus

flavicaudus. The arrows show the three main frequencies in each sound
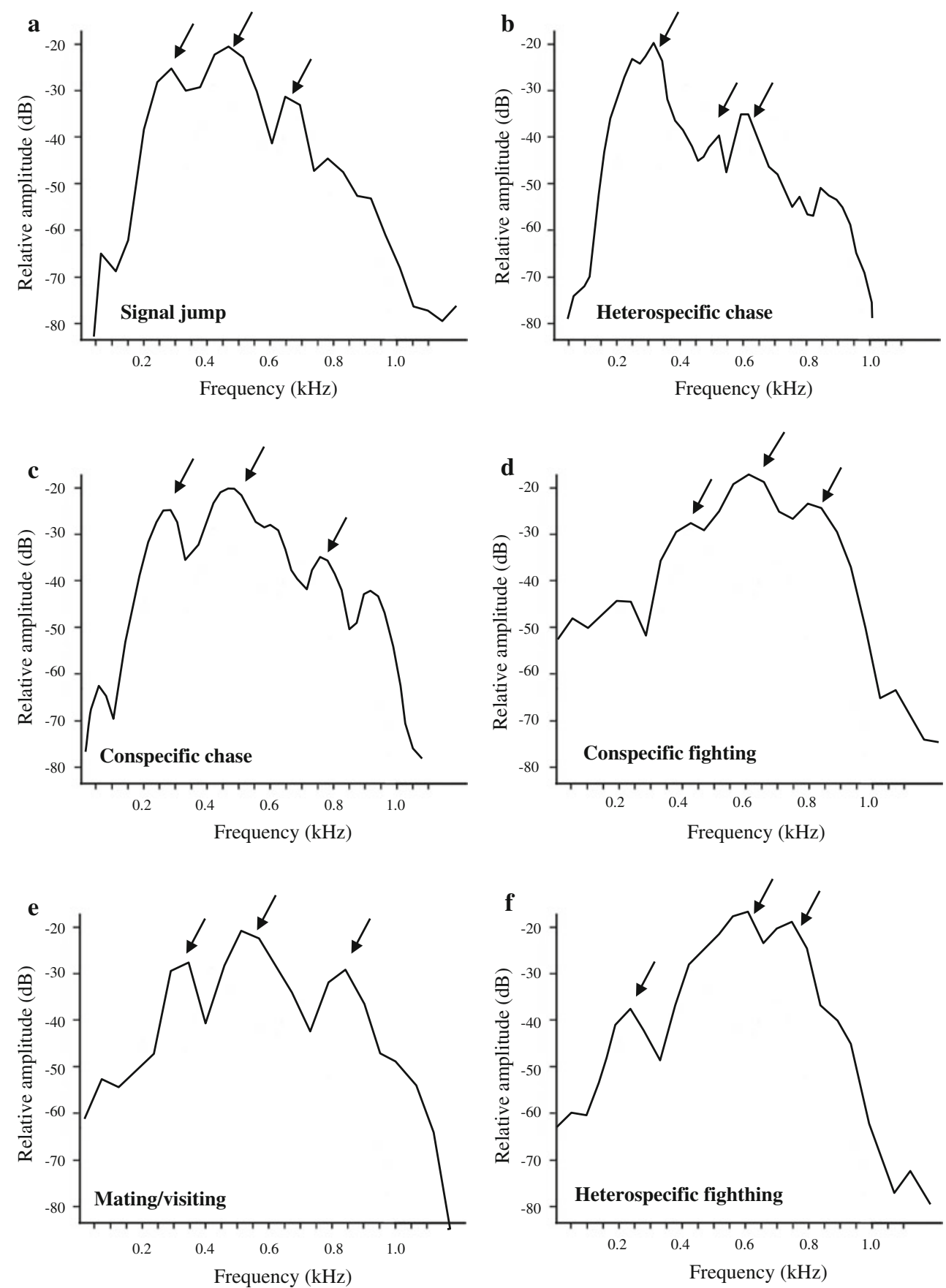

this hypothesis. These sounds mainly have only one pulse, corresponding to the bite the fish intends to make.

Conspecific chase and signal jump calls (corresponding to courtship displays) are particularly interesting because both sounds present a lot of characteristics in common. Both calls are long sounds with generally more than three pulses and also have a similar pulse period and power spectra. It is possible to discriminate between them on the basis of the pulse duration but this characteristic is not reliable (Mann and Lobel 1997). The same authors argued that the pulse period provides the most reliable basis for signal identification. The main difference between the two behaviours, the signal jump and conspecific chase, is not found in the calls but in the associated movements. The signal jump consists of a fish rising in the water column and then rapidly swimming down while making a sound, whereas the chase consists of one fish following another. During courtship behaviour, the fish performs a signal 


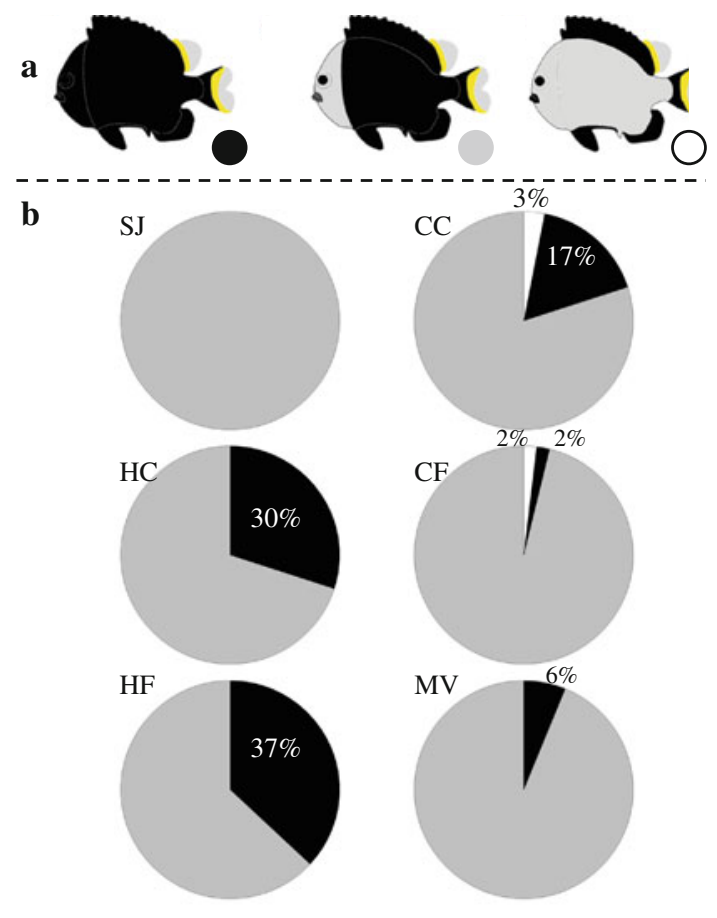

Fig. 6 The three coloured circles in (a) symbolize the three colour patterns adopted by Dascyllus flavicaudus during the call productions. These colours are used in (b) to show the percent frequency distribution of the different patterns during the different kinds of calls. $C C$ conspecific chase, $C F$ conspecific fighting, $H C$ heterospecific chase, $H F$ heterospecific fighting, $M V$ mating-visiting, $S J$ signal jump

Table 2 Determination of the sex in Dascyllus flavicaudus specimens having different colour patterns

\begin{tabular}{|c|c|c|c|}
\hline Gonads & Sex & Colour & $\mathrm{SL}(\mathrm{mm})$ \\
\hline Mature ovaries & Female & $\mathrm{WH}+\mathrm{WB}$ & 67.5 \\
\hline Testes & Male & $\mathrm{WH}+\mathrm{WB}$ & 59 \\
\hline Mature ovaries & Female & $\mathrm{WH}+\mathrm{WB}$ & 70 \\
\hline Mature ovaries & Female & $\mathrm{WH}+\mathrm{WB}$ & 39.5 \\
\hline Ovaries & Female & $\mathrm{WH}+\mathrm{WB}$ & 73.5 \\
\hline Ovaries & Female & $\mathrm{WH}+\mathrm{WB}$ & 67 \\
\hline Ovaries & Female & $\mathrm{WH}+\mathrm{BB}$ & 78 \\
\hline Ovaries & Female & $\mathrm{WH}+\mathrm{BB}$ & 66.5 \\
\hline Testes & Male & $\mathrm{WH}+\mathrm{BB}$ & 83.5 \\
\hline Testes & Male & $\mathrm{WH}+\mathrm{BB}$ & 78 \\
\hline Testes & Male & $\mathrm{WH}+\mathrm{BB}$ & 77.5 \\
\hline Testes & Male & $\mathrm{WH}+\mathrm{BB}$ & 77.5 \\
\hline Mature ovaries & Female & BB & 75 \\
\hline Ovaries & Female & BB & 56 \\
\hline
\end{tabular}

$B B$ black body, $B H$ black body, $S L$ standard length, $W B$ white body, WH white head

jump to attract the female but he also has to swim towards her to motivate her to follow him back and to enable him to show her the nest position. In this case, the courtship sound

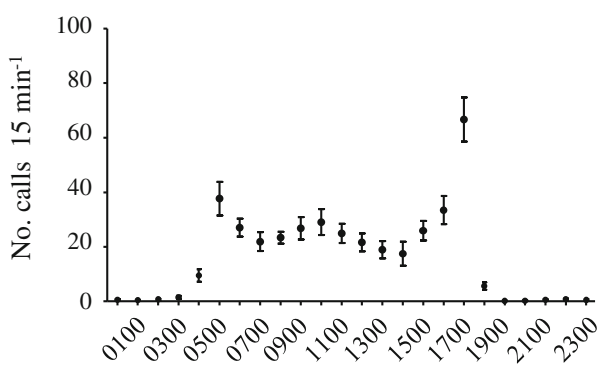

Fig. 7 Mean number of calls produced by Dascyllus flavicaudus during recording periods of $15 \mathrm{~min}$ during the day $(N=40)$. Sunrise was from 0530 to 0600 hours, and sunset was from 1820 to 1840 hours
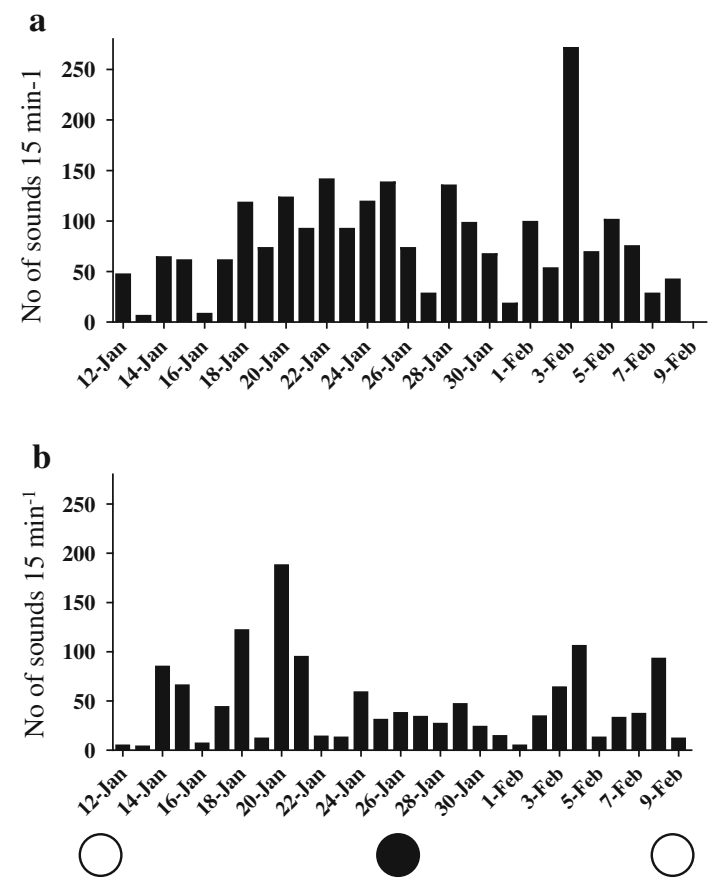

Fig. 8 Number of calls produced in $15 \mathrm{~min}$ by a colony of eight Dascyllus flavicaudus at $6 \mathrm{pm}$ (a) and 6 am (b) during a lunar month. The full and empty circles represent the new and full moon, respectively

resembles the sound made during a chase. This dual function was also questioned by Mann and Lobel (1995), who noted that the signal jump is a courtship sound but that it can be also a territorial signal when females are feeding and are outside of the reproductive season. On the other hand, Dascyllus aruanus males start the signal jump when exposed to other males in bottles (Holzberg 1973; Kenyon 1994), narrowing the line between courtship and chase behaviours. In Pomacentrus partitus, these sounds are also produced by males in their own territories either as an advertisement to females (Myrberg et al. 1986) or as "territorial keepout" signals (Myrberg 1997). The best way to address the difference in the wild would be to refer to the colour pattern of the fish. The signal jump is always 
performed when the fish has a grey (white head and black body) colouration, whereas the conspecific chase can be performed with a black colouration. In this case, the conspecific chase with a greyish colour pattern could be considered to be a part of courtship behaviour. As a minimum, it shows that both behaviours are closely related. Since the signal jump is not performed by all Pomacentridae, this behaviour can be considered as more derived.

Courtship displays are not associated with sound production in Abudefduf abdominalis, but Maruska et al. (2007) observed acoustic behaviours after a female followed the male back to and prior to entry of the nest and that these behaviours continued when the pair was in the nest area. This behaviour can be compared to the mating/ visiting sound of this study. In Stegastes partitus, Myrberg (1972) also described a "grunt" that occurs after a female has entered a male's nest just prior to mating. A mating sound also occurs in Dascyllus albisella; it is produced as the male quivers during spawning (Lobel and Mann 1995; Mann and Lobel 1998). As in D. albisella, the mating sound of Dascyllus flavicaudus differs from the sounds of conspecific chases and courtship mainly at the level of the number of pulses and consequently in the call duration. In addition, the sound level is lower and the period longer in the mating/visiting sound than in the conspecific chase/ courtship sound in D. flavicaudus. Mann and Lobel (1998) discovered a difference between the visiting and the mating sound in D. albisella whereby the period of the mating sound is longer than in the visiting or courtship sound. This difference in the sound period is important because it corresponds to a difference in the muscular contraction rate and reflects a difference in physiology, clearly showing that there is a modification in the behavioural category. Also, this difference in the pulse rate could help to coordinate spawning.

The signal jump and corresponding courtship sounds are used to attract as potential mates females from outside the male's territory. These sounds have more pulses with higher amplitudes which have an effect over great distances. Kenyon (1994) showed in Stegastes partitus that mating sounds attract other males to the nest, although this is not the case with the courtship sound. This could also explain the reason why the mating/visiting sounds are more discrete, showing fewer pulses and a lower amplitude.

The question arises as to which call (MV or SJ/chase) appeared first and is thus closer to the fighting call. The heterospecific fighting call is excluded from this reasoning because the messages considered here are intraspecific. The pulse period seems to be the most reliable characteristic for signal identification (Mann and Lobel 1997) and thus for message information. The pulse period is closer between MV and fighting than between fighting and $\mathrm{SJ} / \mathrm{ch}$ ases (Table 1). Moreover, the number of pulses in MV is three, which is intermediate between the fighting calls and SJ/chase calls (Fig. 2). The hypothesis is that the fighting call appeared first, then the MV sounds. From the call point of view, the MV sound corresponds mainly to the addition of pulses and a lowering in amplitude. After that, a rise in the number of pulses and a shortening of the period would have created the third group of sounds: SJ/chases. This means that the evolution of call diversification would not correspond to the successive behaviours leading to spawning.

\section{Colour pattern}

According to Lobel (1992), the colour pattern associated to the sounds could be used to distinguish sympatric species during spawning. A change in colouration while making sounds has been observed in different damselfishes (Burke and Bright 1972; Spanier 1979; Lobel and Kerr 1999, Parmentier et al. 2009), but this is not always the case. Moreover, the change in colouration is not automatically associated with sounds. All these variations can preclude different kinds of behaviour or show different levels of motivation for the same behaviour. Typically, the pattern of Dascyllus flavicaudus colouration is a dark head and body but males and females can both show at least three different colour patterns, and the fish can produce at least six different kinds of sound. The sounds analysed in this study were arbitrarily attributed to the males because they prepare the nests, they defend the territory and they engage in courtship. The pomacentrid females may also produce sounds simply because they possess the morphology to do so. Moreover, most Dascyllus species change sex during their lifetime (e.g. Asoh 2004). Also, in certain pomacentrid species such as the anemonefishes, the females actively participate in the anemone's defence by making sounds (Parmentier et al. 2005; Colleye et al. 2009). According to these pieces of information, 2 genders - 3 pattern colours-6 different sounds, the species has the potential to make different combinations and produce 36 different messages, 42 if we consider that the pattern of colouration can be shown without any sound. In Fig. 5, it is clearly shown that the sounds we have associated with the conspecific chase behaviour can be made with three different patterns of colouration, masking perhaps three different kinds of message. This potential may be overestimated because it is likely that some sounds (or the colour pattern) are used only to reinforce a given cue and not to create a different one.

\section{Call cycles}

The daily cycle showed that this species made sounds mainly during the day with a peak of activity at sunset 
and a second, higher one, at sunrise. This part of the behaviour differs from that of Dascyllus albisella, which produces sounds mainly in the morning (Mann and Lobel 1995). Sound production was also detected at night in this species and was most intense just before spawning. This difference in sonic activity could be explained by a speciation event because Dascyllus species present sounds with large overlaps in their characteristics (Parmentier et al. 2009). Making sounds at different times of the day could be a system used to avoid misidentification. Dascyllus albisella and D. flavicaudus are not sympatric. The comparison of $D$. trimaculatus and $D$. aruanus, which are sympatric, with $D$. flavicaudus would give more insight into this hypothesis.

A detailed examination of the daily cycle obtained more precise information on D. flavicaudus behaviour. The sounds produced in the early morning are mainly composed of three pulses, likely to correspond to mating/visiting behaviour, whereas sounds produced in the evening mainly correspond to courtship or conspecific chase behaviour. The lack of sound during the night could also indicate that $D$. flavicaudus larvae, which mainly settle during the night (Dufour and Galzin 1993), cannot use this clue to find their conspecifics. The larvae mainly settle on the reef during the new moon period, but it clearly apparent that the number of sounds produced at sunset following the nights of a new moon is not very high. This leads to the assumption that the adults do not intentionally emit messages to their conspecific larvae. It remains possible that the larvae intercept their conspecific sounds in order to orientate towards the adults.

In $D$. albisella, the pattern of sound production is predictive of the timing of spawning on a daily basis for the fish studied. Mann and Lobel (1995) noted that their results corroborated data from Dascyllus trimaculatus and Dascyllus marginatus, which also show increased courtship activity on days of spawning (Fricke 1973; Holzberg 1973). These results cannot be confirmed in this study because the recordings concerned colonies and not individual males.

Acknowledgments We thank the CRIOBE team for their assistance during the study. E. P. is a research associate of the Fonds National de la Recherche Scientifique of Belgium (FRS-FNRS). This study was supported by "starting grants" from the University of Liège and by a grant from the CRISP program, ANR (ANR-06-JCJC-0012-01) and MOM (06 PF 15).

\section{References}

Amorim MCP (2006) Diversity of sound production in fish. In: Ladich F, Collin SP, Moller P, Kapoor BG (eds) Fish communication. Science Publisher, Enfield, pp 71-105
Asoh K (2004) Gonadal development in the coral reef damselfish Dascyllus flavicaudus from Moorea, French Polynesia. Mar Biol 146:167-179

Booth DJ (1991) The effect of sampling frequency on estimates of recruitment of the domino damselfish Dascyllus albisella. J Exp Mar Biol Ecol 145:149-159

Brothers E, DMcB Williams, Sale PF (1983) Length of larval life in twelve families of fishes at "One Tree Lagoon", Great Barrier Reef, Australia. Mar Biol 76:319-324

Burke T, Bright T (1972) Sound production and color changes in the dusky damselfish. Hydr Lab J 1:21-29

Colleye O, Frederich B, Vandewalle P, Casadevall M, Parmentier E (2009) Agonistic sounds in the skunk clownfish Amphiprion akallopisos: size-related variation in acoustic features. J Fish Biol 74:1-9

Doherty P, Williams D (1988) The replenishment of coral reef fish populations. Oceanogr Mar Ann Rev 26:487-551

Dufour V, Galzin R (1993) Colonization patterns of reef fish larvae to the lagoon at Moorea Island, French Polynesia. Mar Ecol Prog Ser 102:143-152

Fine ML, Thorson RF (2008) Use of passive acoustics for assessing behavioral interactions in individual toadfish. Trans Am Fish Soc 137:627-637

Fricke HW (1973) Okologie und sozialverhalten des korallenbarsches Dascyllus trimaculatus. Z Tierpsychol 32:225-256

Gannon DP (2008) Passive acoustic techniques in fisheries science: a review and prospectus. Trans Am Fish Soc 137:638-656

Ha SJ (1973) Aspects of sound communication in the damselfish Eupomacentrus partitus. Dissertation, University of Miami, Miami

Holzberg S (1973) Beobachtungen zur ökologie und zum socialverhalten des Korallenbarsches Dascyllus marginatus Ruppell (Pisces; Pomacentridae). Z Tierpsychol 33:492-513

Kenyon T (1994) The significance of sound interception to males of the bicolor damselfish, Pomacentrus partitus, during courtship. Environ Biol Fish 40:391-405

Lobel P (1992) Sound produced by spawning fishes. Environ Biol Fish 33:351-358

Lobel P, Kerr L (1999) Courtship sounds of the pacific damselfish, Abudebduf sordidus (Pomacentridae). Biol Bull 197:242

Lobel P, Mann D (1995) Spawning sound of the damselfish, Dascyllus albisella (Pomacentridae). Bioacoustics 6:187-198

Mann D, Lobel P (1995) Passive acoustic detection of sounds produced by the damselfish, Dascyllus albisella (Pomacentridae). Bioacoustics 6:199-213

Mann D, Lobel P (1997) Propagation of damselfish (Pomacentridae) courtship sounds. J Acoust Soc Am 101:3783-3791

Mann D, Lobel P (1998) Acoustic behaviour of the damselfish Dascyllus albisella: behavioural and geographic variation. Environ Biol Fish 51:421-428

Maruska K, Boyle KS, Dewan LR, Tricas TC (2007) Sound production and spectral hearing sensitivity in the Hawaiian sergeant damselfish Abudefduf abdominalis. J Exp Biol 210:3990-4004

Myrberg AA (1972) Ethology of the bicolor damselfish Eupomacentrus partitus (Pisces: Pomacentridae): a comparative analysis of laboratory and field behavior. Anim Behav 5:197-283

Myrberg AA (1997) Sound production by a coral reef fish (Pomacentrus partitus): evidence for a vocal, territorial "keep-out" signal. Bull Mar Sci 60:1017-1025

Myrberg AA, Spires JY (1972) Sound discrimination by the bicolor damselfish, Eupomacentrus partitus. J Exp Biol 57:727-735

Myrberg AA, Spanier E, Ha SJ (1978) Temporal patterning in acoustic communication. In: Reese ES, Lighter FJ (eds) Contrasts in behaviour. Wiley, New York, pp 137-179

Myrberg AA, Mohler M, Catala JD (1986) Sound production by males of a coral reef fish (Pomacentrus partitus): its significance to females. Anim Behav 34:913-923 
Myrberg AA, Ha S, Shamblott MJ (1993) The sounds of bicolor damselfish (Pomacentrus partitus): predictors of body size and a spectral basis for individual recognition and assessment. J Acoust Soc Am 94:3067-3070

Parmentier E, Lagardère JP, Vandewalle P, Fine ML (2005) Geographical variation in sound production in the anemonefish Amphiprion akallopisos. Proc R Soc Lond B 272:1697-1703

Parmentier E, Vandewalle P, Frédérich B, Fine ML (2006) Sound production in two species of damselfishes (Pomacentridae): Plectroglyphidodon lacrymatus and Dascyllus aruanus. J Fish Biol 69:491-503

Parmentier E, Colleye O, Fine ML, Frédérich B, Vandewalle P, Herrel A (2007) Sound production in the clownfish Amphiprion clarkii. Science 316:1006

Parmentier E, Lecchini D, Frédérich B, Brié C, Mann D (2009) Sound production in four Dascyllus species: phyletic relationships? Biol J Linn Soc 97:928-940
Schmitt RJ, Holbrook SJ (1999) Temporal patterns of settlement of three species of damselfish of the genus Dascyllus (Pomacentridae) in the coral reefs of French Polynesia. In: Seret B, Sire JY (eds) Proceedings of the 5th Indo-Pacific Fish Conference, Noumea. Société française d'ichtyologie, Paris, pp 537-551

Spanier E (1979) Aspects of species recognition by sound in four species of damselfishes, genus Eupomacentrus (Pisces: Pomacentridae). Z Tierpsychol 51:301-316

Steinberg JC, Cummings WC, Brahy BD, Spires JYM (1965) Further bioacoustic studies off the west coast of North Bimini, Bahamas. Bull Mar Sci 15:942-963

Thresher E (1984) Reproduction in reef fishes. TFH Publisher, Neptune City

Wellington G, Victor B (1989) Planktonic larval duration of one hundred species of Pacific and Atlantic damselfishes (Pomacentridae). Mar Biol 101:557-567 